\title{
SOBRE NARRATIVA DE COLEGIOS JESUITAS EN PÉREZ DE AYALA Y MIRÓ
}

\author{
Fermín EzPeleta Aguilar \\ Universidad de Zaragoza
}

\begin{abstract}
RESUMEN
La novela lírica, que caracteriza la producción literaria de Ramón Pérez de Ayala y Gabriel Miró, sirve a estos autores como estructura que acoge sus iniciales novelas autobiográficas de colegios jesuitas, particularmente, A.M.D.G. y Amores de Antón Hernando (posteriormente, Niño y grande). Se trata en los dos casos de novelas de aprendizaje, que se acercan a la modalidad «de artista», en las que se impugna, mediante recursos como la parodia y la ironía, la pedagogía jesuita. Importa, más en Pérez de Ayala que en Miró, el hilvanado de cuadros estudiantiles con anécdotas académicas de tipos docentes y discentes, al modo de las novelas de costumbres universitarias del momento. Se evidencia en ambos autores cómo el nuevo modo de novelar sigue aprovechando elementos de la tradición realista y naturalista del siglo xIX. Palabras-clave: Ramón Pérez de Ayala, Gabriel Miró, colegios jesuitas, novela lírica, novela de formación, novela de artista.
\end{abstract}

\begin{abstract}
The lyrical novel, which characterizes the literary production of Ramón Pérez de Ayala and Gabriel Miró, these authors serves as a structure that welcomes their initial autobiographical novels of Jesuit schools, particularly A.M.D.G. and Amores de Antón Hernando (later Niño y grande). It is in both cases Bildungsromane that are close to the mode «artist», which is challenged by resources such as parody and irony Jesuit pedagogy. In these novels is important composition of student academic painting with stories as they appear in the novels of university customs of the moment. It is evident in how both authors romanticize the new mode continues to build elements of the realist tradition and naturalist of the nineteenth century. Key words: Ramón Pérez de Ayala, Gabriel Miró, Jesuit schools, lyrical novel, Bildungsroman, Künstlerroman.
\end{abstract}

\section{Novela lírica}

Tiene razón García de la Concha cuando señala un humus generacional en el que se asienta la narrativa novecentista, y de la que brotan, a través de reflexiones y análisis cercanos a lo ensayístico, los diagnósticos sobre la realidad histórica cultural y educativa. Se trata de una «estructura lírica» que actúa «como sustrato común de la literaturidad del $14 »^{1}$ y alcanza de pleno a la novelística de Miró y de Pérez de Ayala, Recibido 28-XI-2014. Aceptado: 24-III-2015

1 V. García de la Concha, «Pérez de Ayala y el compromiso generacional», Los Cuadernos del Norte, I, 
que de igual modo que la de Azorín o Azaña, se inserta como ejemplo hispánico en el gran tronco común de la novela lírica europea.

La narrativa de Pérez de Ayala testimonia desde la tetralogía de Alberto Díaz de Guzmán (Tinieblas en las cumbres, en 1907; A.M.D.G., en 1910; La pata de la raposa, en 1911 y Troteras y danzaderas, en 1913) la vocación estética de modernidad, avalada por el uso y asimilación de las técnicas narrativas de la nueva novela «modernista», aunque en los primeros momentos la crítica acumule un buen número de etiquetas no del todo esclarecedoras para caracterizar la condición narrativa del autor. ${ }^{2}$ Ricardo Gullón, que capta la esencialidad de la novela lírica de Pérez de Ayala, observa cómo la trayectoria formativa de un personaje en su tránsito de la inocencia al conocimiento es uno de los esquemas más adecuados para presentar la absorción de la experiencia, tal como exige la novela lírica. El crítico lo ejemplifica en la novela Urbano y Simona (1923), que tiene por tema la educación sentimental del personaje. ${ }^{3}$ Pero esta nueva estética se ejemplifica igualmente en la novela A.M.D.G. (1910), que forma parte de la tetralogía mencionada, caracterizada por un tratamiento novedoso del tiempo. ${ }^{4}$ Se trata de una novela que supera la estética realista y que incluso intuye genialmente algunos de los recursos básicos de la narración cinematográfica. ${ }^{5}$

Como en Miró, el autor busca estructuras narrativas de Künstlerroman para canalizar «el problema del artista en el mundo moderno dentro del solar hispano», ${ }^{6}$ y para buscar perspectivas privilegiadas que permitan el desarrollo del espíritu de indagación y de toma de conciencia. De hecho A.M.D.G. se convierte de algún modo en genial anticipo de una novela de artista ajustada a la estética de la renovación europea, como es A Portrait of the Artist as a Young Man (1916) de Joyce, con similitudes no sólo en la anécdota argumental, sino también de algunos «refinamientos retóricos» similares en las obras de Ayala y Joyce, aunque con diferencias de tono mucho más sustantivas. ${ }^{7}$

2 (1980), pp. 34-39; y «La poesía de D. Ramón Pérez de Ayala», en AA. DD., Pérez de Ayala visto en su centenario 1880-1980, Oviedo, Instituto de Estudios Asturianos, 1981, p. 174.

2 J. J. Macklin, «Pérez de Ayala y la novela modernista europea», Cuadernos Hispanoamericanos, 367-368 (en.-feb. 1981), p.21; y C. Longhurst, (2008): «The Early Twentieth-Century Novel», en M. E. Altisent (ed.), A Companion to the Twentieth-Century Spanish Novel, Woodbridge, Tamesis, 2008, p. 31.

3 R. Gullón, «Ramón Pérez de Ayala y la novela lírica», en P. H. Fernández (ed.), Simposio Internacional Ramón Pérez de Ayala, Gijón, University of New Mexico, 1981, pp. 61-69.

4 M. C. Bobes, «Sintaxis temporal en las primeras novelas de Ramón Pérez de Ayala», Ínsula, 404-405 (1980), pp. 1 y 30.

5 M. C. Bobes, «Técnicas cinematográficas en las primeras novelas de Ramón Pérez de Ayala», Los Cuadernos del Norte, I, 2 (1980), pp. 26-29.

6 D. L. Fabian, «The progress of the artist: A mayor theme in the early novels of Pérez de Ayala», Hispanic Review, XXVI (1958), pp. 108-116.

7 R. J. Schork, R. J. «Ayala's Joycean Portrait: A.M.D.G.», Comparative Literature Studies, 26, (1989), pp. 
El autor, como casi todos los otros de su generación, remite a la autobiografía para «plantear un conflicto de conciencia y un rechazo de ese mundo» ${ }^{8}$ a través del tema de la búsqueda de identidad del adolescente. Ahora bien, las preocupaciones de ese artista adolescente que es Alberto Díaz de Guzmán echan el ancla, al modo noventayochista, en el problema de España, asunto que nunca desaparece del todo en la obra posterior del escritor. ${ }^{9}$ La exclusión de A.M.D.G. por la censura franquista de las obras completas de Ayala, aparte de otorgar al texto un aura especial, ha privado durante algún tiempo a los lectores comunes de una comprensión de la serie narrativa de Alberto Díaz de Guzmán como unidad textual; sin embargo, una vez entregada al lector por parte de Andrés Amorós ${ }^{10}$ cincuenta años después de la edición de 1931, se dibuja con más claridad el esquema de aprendizaje artístico (novela de artista o Künstlerroman) que modela la historia de Bertuco, quien se presenta como un ser que indaga y se busca, oscilante entre la vocación de pintor y de escritor.

De igual modo, Gabriel Miró ocupa como narrador «una privilegiada situación de adelantado» dentro del Modernismo europeo ${ }^{11}$ y absorbe todas y cada una de las marcas estudiadas por Ricardo Gullón y Darío Villanueva en sus libros clásicos sobre la novela lírica. Este último crítico identifica la novela lírica con «una singular manifestación del Bildungsroman o novela de aprendizaje: el relato autobiográfico de la constitución de una sensibilidad artística personificada en un personaje emblemático, alter ego del autor»; ${ }^{12}$ aspecto este en el que incide de igual modo Gullón. ${ }^{13}$ El predominio del «personaje pasivo»; la modulación de figuras literarias hechuras del propio autor, como es el caso del Sigüenza que forma la conocida trilogía (Del vivir, 1904; Libro de Sigüenza, 1917; y Años y leguas, 1928) y de otros personajes que remiten a la zona autobiográfica mediante un entramado literario, aglutinado en torno a la «narrativa de la memoria» ${ }^{14}$ para conformar una suerte de «geografías de la

50-70. Es verdad que la novela de Joyce se redactó entre 1904 y 1914 (traducida al español por Dámaso Alonso en 1926) y que, en el ámbito europeo, surge en fechas previas a la novela de Pérez de Ayala un grupo de novelas de artista de alta calidad que glosan el refugio del protagonista en su propio yo como medio de superar el peso de los severos modos educativos del internado religioso. Entre otras, Tonio Kröger de Mann (1903); Törless (1906); Jakob von Gunten de Robert Walser (1909). Ver el libro de F. Moretti, Il romanzo di formazione, Torino, Einaudi, 1999, especialmente el último capítulo («Un’ inutile nostalgia di me mesmo. La crisi del romanzo di formazione europeo, 1898-1914», pp. 257-273).

8 A. Amorós, La novela intelectual de Ramón Pérez de Ayala, Madrid, Gredos, 1972, p. 396.

9 D. L. Fabian, «Pérez de Ayala and the generation of 1898», Hispania, XLI (1958), pp. 154-159.

10 Editorial Cátedra en 1983, por la que cito en su edición de 1995. R. Pérez de Ayala, A.M.D.G., edición de A. Amorós, Madrid, Cátedra, [1983]1995.

11 M. Á. Lozano Marco, Los inicios de la obra literaria de Gabriel Miró. Del vivir, Alicante, Universidad de Alicante, 2010, p. 41.

12 D. Villanueva, La novela lírica, Madrid, Taurus, 1983, I, p. 14.

13 R. Gullón, La novela lírica, Madrid, Cátedra, 1984, p. 91.

14 F. Barberá, «Gabriel Miró. La narrativa de la memoria», AA DD., Literatura autobiogràfica: Història, 
conciencia»; ${ }^{15}$ la tendencia a la composición fragmentaria que apela al receptor para que este realice el proceso de recomposición de las impresiones y sensaciones que dan cuerpo a la novela ${ }^{16}$ con un resultado de «novela cubista», de la que ha hablado también Casalduero; ${ }^{17}$ el tratamiento dual de lo lírico y lo novelado, con un «yo», en fin, que invade la prosa y que determina su ritmo y su textura. ${ }^{18}$ La acción y el argumento se pierden a favor de una literatura intimista y de confesión que evoluciona hacia una cierta «desnovelización del género». ${ }^{19} \mathrm{El}$ resultado es el de una narración que se nutre de elementos constitutivos de «novela de personaje», el romance (narración introvertida y personal), la autobiografía (narración introvertida e intelectual) y la confesión (trazado espiritual) y que viene siempre abocada a conformar estructuras novelescas de aprendizaje.

Estamos también ante un novelista al que se ha conectado en un determinado momento por parte de la crítica con el 98 (a modo de ejemplo, Becker ${ }^{20}$ ), que da forma literaria a un personaje intelectual que es trasunto de su autor, el cual se topa con dificultades propias de los héroes modernos. Por eso tampoco resulta extraño que cobre protagonismo en toda su obra, y particularmente en las primeras novelas formativas, la figura del personaje artista, tal y como ocurre con la obra de Pérez de Ayala, ${ }^{21}$ con lo cual la modalidad novelesca se decanta, como ocurre con buena parte de la novela lírica y en especial la de temática escolar en internados, hacia el Künstlerroman. ${ }^{22}$ El autor se esfuerza por realzar en sus obras la sensibilidad, simbolizada en el artista colocado frente a la grosería circundante, ${ }^{23}$ hasta el punto de que ese es precisamente el único tema de la obra mironiana. El esteticismo con que se resuelve el ejercicio literario hace

memoria i construcció del subjecte, Alacant, Denes Editorial, 2001, p. 243.

15 R. Johnson, «Las geografías de la conciencia en la obra de Gabriel Miró», en M. A. Lozano (coor.), Actas del II Simposio Internacional Gabriel Miró, Alicante, Caja de Ahorros del Mediterráneo, 2004, p. 129.

16 R. Gullón, «La novela lírica», en D. Villanueva (ed.), La novela lírica, Madrid, Taurus, vol. 1, 1983, p. 245.

17 J. Casalduero, «Miró y el cubismo», en Estudios de literatura española, Madrid, Gredos, 1962, pp. 288332.

18 R. Gullón, op. cit., p. 251.

19 R. Landeira, «La narrativa autobiográfica de Gabriel Miró», Instituto de Estudios Alicantinos, 27, Segunda época (mayo-agosto de 1979), pp. 83-89.

20 A. W. Becker, El hombre y su circunstancia en la obra de Gabriel Miró, Madrid, Revista de Occidente, 1958, p. 20.

21 Así, personajes como Federico Urías de La novela de mi amigo; Aurelio Guzmán de La palma rota; Félix, de Las cerezas del cementerio; Luis, de Dentro del cercado; Agustín, de El abuelo del rey; amén, claro está, de Sigüenza o del protagonista de Niño y grande.

22 F. Márquez Villanueva, «Gabriel Miró y el Künstlerrroman», en M. A. Lozano Marco y R. M. Monzó (eds.), Actas del I Simposio Internacional «Gabriel Miró», 1999, p. 89.

23 J. Matas, «Gabriel Miró y su novela de la sensibilidad poética», en La cuestión del género literario. Casos de las letras hispánicas, Madrid, Gredos, 1979, p. 234. 
difícil encontrar prédica moralizante, puesto que siempre se pone en valor la palabra como un instrumento de conocimiento que anticipa el pensamiento contemporáneo europeo. $^{24}$

Pero Miró, también desde el punto de vista estructural, es capaz de llegar a su máximo de calidad, particularmente en las dos grandes novelas finales de Oleza, tomadas por una sola por la mayor parte de la crítica, con una nueva recreación del elemento religioso jesuítico y fuerte conexión con la novela de internado previa que es Amores de Antón Hernando y su reformulación, Niño y grande.

\section{Pedagogía}

A partir de esta nueva estética, que no renuncia al perspectivismo lírico ${ }^{25} \mathrm{ni}$ a un fuerte yo poemático, ${ }^{26}$ tanto Pérez de Ayala como Miró saben imprimir tempranamente a sus obras literarias un sesgo formativo inequívoco. En el primero de ellos, como en Galdós o en Unamuno, la educación es el gran estímulo de una entera producción artística en la que se incluye A.M.D.G. como hito de la novela pedagógica. Amorós considera que la «obsesión educativa» lleva aparejada en este escritor la novela educativa como el expediente formal más natural para la creación literaria, hasta el punto de que «sin tener en cuenta esta dimensión, no podrán entenderse muchas de las principales características de la obra narrativa de Ayala». ${ }^{27}$

El autor, en efecto, había declarado en 1942 que el propósito del plan total inconcluso de todo este primer tranco de su trayectoria narrativa consistía en «reflejar la crisis de la conciencia hispánica desde principios de este siglo», presentando la evolución de las conciencias individuales desde la mentalidad el siglo XIX hasta otra, "gradualmente definida e intensificada de conciencia nacional e histórica». ${ }^{28} \mathrm{Y}$ ciertamente la actitud de compromiso generacional que lleva al escritor a bajar a la arena de la política integrándose en la Liga de Educación Política (1913) es el corolario que se desprende de esa primera serie narrativa que, sin dejar de acusar elementos

24 R. Johnson, El ser y la palabra en Gabriel Miró, Madrid, Fundamentos, 1985, p. 9.

25 J. R. González, «El perspectivismo lírico de Ramón Pérez de Ayala», Anales de Literatura Española, 22 (2010), p. 171.

26 Á. L. Prieto de Paula, «La hipertrofia del yo: Gabriel Miró y la poesía», en M. L. Lozano (ed.), Nuevas perspectivas sobre Gabriel Miró, 2007, p. 85.

27 A. Amorós, op. cit., 1972, p. 62.

28 V. García de la Concha, «La generación de 1914 y el novecentismo. Los novelistas: Ramón Pérez de Ayala y Gabriel Miró», en F. Rico, (dir.), Historia y crítica de la literatura española, vII, V. García de la Concha, Época contemporánea: 1914-1939, Barcelona, Editorial Crítica, 1984, p. 82. 
narrativos modernos, remite a la gran obsesión pedagógica que propulsa toda la obra del escritor en simbiosis de ética y estética. ${ }^{29}$

En una novela como A.M.D.G., que invoca desde todos los puntos de vista posibles la cuestión pedagógica, se observa, pues, el intento de aunar la reflexión sobre las insuficiencias de la educación religiosa con el arte literario, que pugna por librarse de las ataduras de la estética realista, a menudo a través del recurso de la parodia. ${ }^{30}$ El mensaje último del relato novelado de la experiencia real de su autor como interno en el colegio jesuita de Carrión de los Condes y Gijón se inscribiría dentro de la lucha político-social de la época a favor de la secularización de la enseñanza. El autor forma criterio, a través de los recursos literarios empleados, acerca de cómo la formación verificada en el establecimiento docente jesuítico es el reverso de lo que deba ser una educación auténtica, que necesariamente ha de abrirse a la espontaneidad natural, en sintonía con la tradición institucionista de donde proviene el autor: «Además de un relato autobiográfico, un panfleto antijesuítico y una narración de costumbres colegiales, la novela es -quizás, por encima de toda otra cosa- un ensayo sobre el tipo de educación que proporcionan en España, algunos colegios religiosos». ${ }^{31}$ Es decir, el texto ayaliano puede acercarse al subgénero de novela pedagógica, con tesis $a$ contrario, que muestra por vía negativa cuál debe ser el camino pedagógico avizorado. Y dada la concomitancia que tiene la novela con lo ensayístico, el empleo continuado de la ejemplificación, las ilustraciones gráficas o la omnisciencia narrativa, A.M.D.G. se aproxima asimismo a los ámbitos del tratado pedagógico.

La propuesta educativa de esta novela subyace en realidad en toda la obra literaria de Pérez de Ayala. De ahí que insista, por ejemplo, en el tratamiento del personaje profesor en uno de sus mejores cuentos, «El profesor auxiliar», analizado por Matas. ${ }^{32} \mathrm{Y}$ de ahí que los esquemas narrativos educativos, Bildungsroman y tratado pedagógico, se vuelvan a aprovechar en otras novelas. Particular importancia cobra Los trabajos de Urbano y Simona, con conexiones obvias con Amor y Pedagogía (1902) de Unamuno. ${ }^{33}$ En esta narración ayaliana aparece la pareja pedagógica formada por Don

29 V. García de la Concha, op. cit., 1980, pp. 34-39.

30 Á. A. Ayo, «Parodia en innovación en la primera etapa de la obra de Pérez de Ayala (1902-1913)», Bulletin Hispanique, 114, 1 (2012), p. 375.

31 A. Amorós, op. cit., 1972, p. 140.

32 J. Matas, «Pérez de Ayala y el cuento», Ínsula, 404-405 (1980), p. 7.

33 Los dos autores, Unamuno y Pérez de Ayala, son maestros en el arte de la contraposición y del dualismo y apuestan por un vitalismo apoyado en la inteligencia como desiderátum educativo. En las dos novelas, Amor y Pedagogía y Los trabajos de Urbano y Simona, se afirma el triunfo de la naturaleza. En Unamuno no hay posibilidad de rectificación, al no caber el final feliz; en Pérez de Ayala, sus héroes verifican su falta de autenticidad para finalmente convertirse a los nuevos valores. Ver C. Díaz Castañón, «Amor, educación, pedagogía», Los Cuadernos del Norte, I, 2 (jun-jul 1980), p. 20. 
Cástulo, como preceptor, y Urbano, como discípulo. Algo parecido puede decirse de Prometeo (1916), una de las novelas poemáticas que presenta un final muy parecido también al de Amor y Pedagogía, igualmente señalado por la crítica. ${ }^{34}$

A.M.D.G. bebe de forma nítida en la corriente literaria antijesuítica que había suministrado algunos títulos de novelas, con especial carga virulenta al amparo de la estética naturalista en alguna muestra de narración escondida en los periódicos ${ }^{35}$ (Jesús. Memorias de un jesuita novicio, del periodista Dionisio Pérez, 1898). ${ }^{36}$ Por otro lado, la literatura antijesuita da pie a una serie de polémicas literarias que continuaron a lo largo del primer tramo del siglo xx. Y es que, de acuerdo con Amorós, ${ }^{37}$ la obra de Ayala tiene evidente conexión con la novela realista de tesis anticlerical, estudiada en el clásico libro de Dendle de 1968. Hay anticlericalismo en A.M.D.G., matizado acertadamente por Fernández Avello, al señalar que constituye tal actitud «una de las claves diferenciadoras y esclarecedoras, aunque no sea el componente determinante de su obra». ${ }^{38} \mathrm{Y}$ es que, como ocurre con El jardín de los frailes (1927) de Azaña, más que el alegato anticlerical importa la impugnación de la falsificación pedagógica que se desprende del relato. ${ }^{39}$

En el caso de Gabriel Miró, la pulsión pedagógica se funde igualmente en el anhelo de perfección estética, al hilo del recuerdo de las experiencias personales que le dejan huella. Y, como en A.M.D.G. y las «novelas gemelas ${ }^{40}$ de los demás autores

34 E. Rodríguez Monescillo, «El humanismo griego en Ramón Pérez de Ayala», Ínsula, 404-405 (1980), p. 8. Esta autora insiste en la base común de humanismo griego entre Unamuno y Pérez de Ayala. Para las conexiones de Amor y pedagogía con Prometeo, ver D. L. Fabian (1958): «Action and Idea in Amor y pedagogía and Prometeo», Hispania, XLI (1958), pp. 30-34; M. L. Gil, «La educación como materia novelesca (Paul Bourget-Unamuno- Pérez de Ayala)», Cuadernos Hispanoamericanos, CXVI, 348 (1979), pp. 596-608; y Albiac, quien considera que ambas narraciones tratan del fracaso de la fe en la ciencia y se resuelven como alegorías del castigo a quien proclama la superioridad de la ciencia sobre la vida eterna. Ver M. D. Albiac, «Perseo y el espejo. Autobiografía y literatura en la preguerra europea», en AA. DD, La novela en España (Siglos XIX y XX), Actas, Madrid, Casa de Velázquez, 2001, pp. 118-125.

${ }^{35}$ Ver, para la literatura antijesuítica de ese periodo, el libro de J. L. Molina Martínez, Anticlericalismo y literatura en el siglo XIX, Murcia, Servicio de Publicaciones Universidad, 1998, especialmente el apartado «Jesuitismo y Literatura», dentro del capítulo cuatro.

36 Es operativa la traducción al español de la obra francesa canónica de la literatura antijesuítica naturalista, Sebastián Roch (1890) de Octavio Mirbeau, a partir de 1900.

37 A. Amorós, «Introducción» a A.M.D.G. de Ramón Pérez de Ayala, Madrid, Cátedra, 1995, pp. 22-33.

38 M. Fernández Avello, El anticlericalismo de Pérez de Ayala, Oviedo, Gráficas Summa, 1975, pp. 11-12.

39 G. García Aguayo, «El jardín de los frailes versus A.M.D.G», Ínsula, XLV, 526 (1990), p. 16.

40 Senabre conecta Mario en el foso de los leones, de F. C. Sainz de Robles, con El jardín de los frailes, A.M. D.G., El obispo leproso y El convidado de papel (R. Senabre, Lengua y estilo de Ortega y Gasset, Salamanca, Acta Salmanticiensia, 1964, p. 27). Mainer insiste en la relación de parentesco que presentan novelas como A.M.D.G., El jardín de los frailes, Nuestro Padre San Daniel, El obispo leproso y El convidado de papel (J. C., Mainer, «Introducción» a El convidado de papel, de Benjamín Jarnés, Zaragoza, Guara Editorial, 1979, p. 13). Para el panorama de la novela novecentista de internado (F. Ezpeleta, «El jardín de los frailes de Azaña en la novelística novecentista de internados religiosos», Revista de Literatura, 148 (2012), pp. 497-516. 
que componen sus memorias escolares, el asunto novelesco de Niño y grande (1922), versión definitiva de la primitiva de 1909, Amores de Antón Hernando, remite al paso por el internado religioso del Miró escolar durante los años infantiles, con el resultado asimismo de novela de aprendizaje. ${ }^{41}$ Se trata también de un internado jesuita: el centro educativo es el Colegio de Santo Domingo de Orihuela. Se ha considerado por la crítica el lazo poderoso que une a Miró con aquella vivencia como interno en el colegio de Orihuela entre 1887 y $1892 .{ }^{42}$ Tal experiencia, al entender de King, ${ }^{43}$ posibilita al autor una formación sólida al familiarizarlo con los clásicos latinos. Y, en cierto modo, se convierte en estímulo de su vocación artística. Aun así, el escolar acusa el impacto de la vida austera y represiva y proclama con claridad su disconformidad con los modos pedagógicos jesuíticos: el propio niño pide a sus padres que lo saquen del colegio para completar el bachillerato en el instituto de Alicante.

Suelen coincidir los críticos en que la nueva formulación de la novela supone un proceso de depuración estética que hace de la versión de 1922 una obra más lograda literariamente. Aunque en la versión de 1909 se anuncia ya la persecución del ideal amoroso, es en la nueva reformulación donde se redondea la experiencia erótica de Antón, de modo que como ocurre en Pequeñas memorias de Tarín (1915) de Sánchez Mazas, la educación vital y sentimental sustituye pronto a las instancias educadoras académicas. La tercera parte (y estamos hablando ya de Niño y grande ${ }^{44}$ ) tiene «un retrato más acabado y más matizado del protagonista y, al mismo tiempo, la posibilidad de introducir nuevos personajes y nuevos amores» ${ }^{45}$ y ayuda a reforzar el valor estético de las dos primeras partes (Amores de Antón Hernando). Si en la primera parte el ideal amoroso del escolar tomaba cuerpo en la hermana del compañero Bellver, Elena; la segunda propicia un aprendizaje de iniciación sexual con la hermosa esposa del vecino Sr. Requena, doña Francisca, envuelto en andamiaje naturalista. ${ }^{46}$

Es verdad que el mundo religioso oriolano, galvanizado por la Compañía de Jesús, impregna todavía más las dos novelas de Oleza de 1921 y 1926 (Nuestro Padre San

\footnotetext{
41 J. Juan Penalva, «Niño y grande como novela de aprendizaje (Miró frente a Joyce y Pérez de Ayala. Educación en un colegio de Jesuitas)», en E. M. Tondá y A. Mula (eds.), Scripta in memoriam. Homenaje al profesor Jesús de Vera Ferré, Universidad de Alicante, 2001, p. 593.

42 I. Macdonald, «Introducción» a la edición de El obispo leproso de G. Miró, Fundación Cultural Caja de Ahorros del Mediterráneo, Instituto de Cultura Juan Gil-Albert, 1994, pp. 19 y ss.

43 E. L. King, «Gabriel Miró y los ejercicios espirituales», Boletín del Semanario de Derecho Político, 26 (1962), pp. 95-102.

44 Cito por la edición de C. Ruiz Silva, Niño y Grande, Madrid, Castalia, 1987.

45 C. Ruiz Silva, op. cit., p. 29.

46 Ver, para los aspectos naturalistas de la novela, M. Montes Huidobro, «Miró: naturalismo estético-romántico en Niño y grande», Hispania, 59 (1976), p. 452.
} 
Daniel y El obispo leproso ${ }^{47}$ ), especialmente la segunda, en lo que se refiere a las maneras educativas del Colegio de Santo Domingo. Toda la acción, tanto en Nuestro Padre San Daniel como en El obispo leproso, está marcada por el influjo negativo de la religión que empapa todas las actitudes y comportamientos de los personajes. El tema común de ambas es la sofocante opresión producida por los jesuitas y eclesiásticos. ${ }^{48}$ Tal asfixia, a la que también coadyuva el ambiente, impide la consecución de la felicidad por los personajes más sensibles. ${ }^{49}$ El viejo colegio de Santo Domingo funciona así como microcosmos de todo el espacio olecense, caracterizado por las notas opresivas, en contraste con la exuberancia de la naturaleza.

El Pablo escolar que busca miradores al aire libre remite igualmente a la experiencia infantil del autor; pero en Amores de Antón Hernando y su reformulación final de Niño y grande, es donde se focaliza más explícitamente el día a día de la institución académica. Así pues, la crítica antijesuítica se localiza principalmente en estas novelas, situadas en el inicio y en el final de toda la trayectoria del escritor. Con todo, conviene no echar en el olvido las estampas que hilvanan el Libro de Sigüenza, en las que aparece considerado este mismo motivo. Sobre todo, el cuento «El señor Cuenca y su sucesor». ${ }^{0}$ El título completo es «El señor Cuenca y su sucesor (Enseñanza)» y, a través de este paréntesis explicativo, se señala inequívocamente el contenido pedagógico subyacente. Es «toda una memoria» que remite a la autobiografía personal ${ }^{51}$ sobre la metodología pedagógica llevada a cabo por los jesuitas en el colegio de Orihuela.

Miró, de igual modo que Pérez de Ayala, participa de esa corriente novelística que arranca de la novela de tesis religiosa posterior a la Revolución del 68, que se modula a lo largo del resto del siglo XIX y durante los treinta primeros años del xx, y que desemboca en una literatura anticlerical asociada a la novela autobiográfica. El escritor levantino se siente concernido por los aspectos candentes de la vida española y, claro está, el de la educación es uno de ellos, y no el menos importante.

47 Cito por la edición de M. Ruiz Funes, «Introducción» a El obispo leproso, Madrid, Cátedra, 1989.

48 I. Elizalde, «Gabriel Miró y los jesuitas», Revista de Literatura, XLIII, 86 (1981), p. 184.

49 Otros testimonios literarios que transcriben la vida de los colegios jesuitas lo aporta Luis Astrana Marín, autor en 1915 de una «novela», o informe novelado, que lleva el título de La vida en los conventos y seminarios (Memorias de un colegial), con un yo autobiográfico testigo de lo que presencia. Un tono más amable presenta un cuento poco conocido que por esas fechas compone un joven Juan Antonio de Zunzunegui (El binomio de Newton, 1925) con indagación de costumbres escolares jesuíticas y buena investigación de modos educativos: toma de la lección, ternas, inspectores de noche y castigos. Como contrarréplica importante a este tipo de literatura hay que señalar la novela pro-jesuítica, Los caballeros de Loyola (1929), de Rafael Pérez y Pérez.

50 En «El enlutado y el perejil» (capítulo integrado también en El libro de Sigüenza) hay asimismo evocación de rezos escolares, impregnados de la idea de la muerte.

51 R. Landeira, Gabriel Miró: Trilogía de Sigüenza, Chapel Hill, Ediciones de Hispanófila, 1972, p. 66. 
El poso pedagógico se pone asimismo de manifiesto a lo largo del resto de la obra mironiana y, por ejemplo, no se sustrae al tratamiento literario de la figura magisterial: el motivo del maestro de escuela aparece cuando evoca a sus maestros ${ }^{52}$ Don Francisco Alemany y Don Marcelino, a los que recuerda con un tono cariñoso similar al que mostraba Unamuno al recordar a los suyos. Y, al igual que el Rector de Salamanca, compone un cuentecillo con maestro rural como protagonista. Se trata de «El señor maestro», asimismo adornado de rasgos morales positivos: abnegación, sensibilidad, capacidad de entrega a los escolares y con ausencia, como en «El maestro de Carrasqueda» unamuniano, de alusiones a la difícil condición social de la profesión docente. De forma ocasional, en fin, esboza cuáles han de ser las cualidades que deben adornar al buen maestro (La República de las Letras, 15, Madrid, 22 de julio de 1907; también en El Lugar Hallado, Polop, 1952), con subrayado de la noble misión que le cabe desempeñar. No hay que olvidar que Miró también se ve envuelto en una no pequeña polémica periodística de gran trasfondo pedagógico con motivo de la publicación de El obispo leproso. ${ }^{53}$ Esta novela se leyó como un eslabón más de la larga cadena literaria antijesuítica, en la que no faltan hitos de máxima virulencia polémica. Lo mismo que la pieza teatral galdosiana, Electra (1901), A.M.D.G. de Pérez de Ayala o Mirando a Loyola (1913) de Julio Cejador, la novela de Miró suscita un encendido debate de seis meses de duración. ${ }^{54}$

\section{COSTUMBRES ACADÉMICAS Y TIPOS}

En A.M.D.G. hay indagación realista de la práctica docente jesuita desde la óptica de la omnisciencia propia de la gran novela del XIX, aunque el narrador en tercera persona ceda el testigo en un momento determinado a la voz homodiegética a través del recurso de las notas de cuaderno de un colegial que, en los momentos de intimidad, reafirma su sensibilidad artística de escritor en ciernes. El fondo rico de documentación que se deja entrever en esta novela (anécdotas vividas más anécdotas internas de los clérigos, suministradas por un testigo excepcional de primera mano como es Julio Cejador) otorga al texto la sensación de verdad e impregna toda la casuística colegial, con el resultado de un mosaico mucho más jugoso que el que presenta Niño y grande de Miró. En esta línea ha insistido desde el principio Andrés Amorós, quien ha visto que la galería de personajes clérigos profesores gana en eficacia expresiva

52 V. Ramos, El mundo de Gabriel Miró, Madrid, Gredos, 1964, p. 436.

53 La recompone M. Ruiz Funes en su «Introducción» a la novela, op. cit.

${ }_{54}$ C. Ruiz Silva (en op. cit., 24), pone de relieve cómo el nombre de Miró aparece en primera línea periodística con una divisoria entre críticos que se ven impelidos a salir en defensa de la Compañía y otros que contrarrestan los virulentos artículos de defensa. Señala que la polémica perjudica al escritor en su carrera literaria, hasta el punto de verse privado de la elección como académico de la lengua. 
por la vía realista, al enmascarar cada uno de esos tipos una persona real. Se trata de personajes en clave, ${ }^{55}$ cuyo exponente más evidente es Atienza-Cejador, ${ }^{56}$ pero que alcanza a casi la totalidad de los personajes. ${ }^{57}$ Pérez Ferrero ${ }^{58}$ aporta asimismo en sus estudios abundancia de citas que confirman la condición de testimonio autobiográfico que caracteriza a la novela.

En este sentido, la obra puede leerse como novela de costumbres escolares ${ }^{59}$ en la que lo relevante es la habilidad para tejer, mediante una sarta de anécdotas colegiales, una peripecia costumbrista. La selección de todo este material posibilita el desfile de sacerdotes maestros, caracterizados con eficacia, en tanto que trasuntos de personas reales que glosan casi siempre comportamientos o maneras pedagógicas inaceptables. Así, los castigos aflictivos del padre Mur a Bertuco, que precipitan la conclusión de lo narrado, insistiendo en una de las marcas de la serie literaria de internados, son de filiación de la escuela del «siembra coscorrones y recogerás sabios» del personaje Pedro Polo galdosiano de El doctor Centeno (1883).

Aparece el padre Prefecto de disciplina, Conejo, ejemplo de incapacidad pedagógica; o se glosan los comportamientos desviados de alguno de los educadores como el hermano Echevarría; o como Olano, quien intenta abusar sexualmente de Ruth (el capítulo titulado irónicamente «El Libro de Ruth» desarrolla este motivo, recurrente en las novelas de internados religiosos). Se da cabida a la representación de la práctica docente cotidiana, con la puesta en escena del primer día de clase, que tampoco suele faltar en los cuadros de costumbres estudiantiles, sean universitarios o de menor rango; el reparto de libros, los paseos escolares de los jueves, los partidos de pelota, el sistema de premios y castigos, las delaciones (siempre presentes en la literatura antijesuítica) y la fuerte coerción ejercida en nombre de la religión por unos educadores que en poco tiempo, el cuarto año de la puesta en funcionamiento del colegio, muestran la disolución de sus propios principios morales. Estos hechos ocurren en el periodo de un curso escolar, pero aquí, inconcluso, al modo del antiBildugsroman naturalista, para subrayar el fracaso educativo. Y pueden remitir al curso

\footnotetext{
55 A. Amorós, en «Introducción», 1995, pp. 68-75.

56 D. Gamallo Fierros, «Primera etapa de la vida y obra de Pérez de Ayala», en AA. DD., Pérez de Ayala visto en su centenario, Instituto de Estudios Asturianos, 1981, pp. 227-445. Este autor ha insistido también en ponderar la mucha influencia de Cejador en la obra y aun en la vida de Ayala.

57 Constantino Quintela Rodríguez en su Memoria de licenciatura de 1981 ha enriquecido la correspondencia de personajes literarios y personas reales en un trabajo detectivesco, al modo de lo que la crítica había hecho, por ejemplo, con Troteras y danzaderas, novela en la que varios críticos han insistido en poner nombre real a cada uno de los personajes intelectuales que deambulan por el espacio novelesco. (A. Amorós, op. cit., p. 70).

58 M. Pérez Ferrero, Ramón Pérez de Ayala, Madrid, Publicaciones de la Fundación Juan March, 1973, pp. 27-41.
}

59 A. Amorós, op. cit., p. 21. 
real de 1894, en el colegio de Gijón, donde estudió el autor. Un lapso de tiempo que permite estructurar los sucedidos estudiantiles con arreglo a la disposición temporal propia del curso escolar, con sus momentos más significativos.

Al narrador le interesa hacer aflorar rencillas que se producen entre los propios educadores, en contraste con las peleas y bromas estudiantiles, siempre mejor intencionadas que las de sus maestros. Alguno de los tipos estudiantiles aparece abocetado a la manera costumbrista; es el caso de Coste, «el gallego estudiantón y molletudo», que parece prefigurar alguno de los integrantes de la estudiantina de $\mathrm{La}$ casa de la Troya (1915), aunque finalmente el personaje sirva a propósito bien distinto y subraye la conclusión trágica. Coste, cuando huye del colegio a lomos del burro Castelar, tras ser castigado por lenguaraz, encuentra la muerte en un acantilado antes de llegar a su Ribadeo natal. El autor, que ha escrito la novela en unas vacaciones de verano en Galicia, recrea en esta parte final el tipo estudiantil gallego con su correspondiente caracterización lingüística. ${ }^{60}$

Hay descripción de las dependencias escolares (los estudios, los pupitres), la comida en el refectorio, ${ }^{61}$ los cargos jesuíticos con su peculiar estratificación (prefectos de disciplina, distributario, maestrillo); o las referencias al tiempo del verano anterior como momento de iniciación sexual de Bertuco (con la hija del jardinero y por indicación del preceptor de verano); el papel subsidiario de los fámulos, las celdas, los momentos de indisciplina escolar; la escenificación del alumnado en los dos bandos de romanos y cartagineses, o la distinción honorífica de «Emperador». ${ }^{62}$ La escenificación de actividades docentes como la distribución de premios y castigos a la manera de Pequeñeces (1891) de Coloma, El obispo leproso (1926) o Mario en el foso de los leones (1925) de Federico Carlos Sainz de Robles; las declamaciones poéticas, fuertemente satirizadas por el narrador; la orquesta del colegio, a cargo de un profesor que imposta un sentimiento y una sensibilidad musicales de los que carece; la aparición, en el exterior, del prostíbulo o el motivo de la atracción sexual por la hermana de un compañero al modo de Niño y grande («Ayer, el papá de Pelayo lo sacó del colegio. Un

\footnotetext{
${ }_{60}$ El tipo del estudiante gallego aparece en las novelas de costumbres universitarias de Santiago de Compostela. Son Pascual López (1878) de Pardo Bazán; El último estudiante (1883) del Marqués de Figueroa o La casa de la Troya (1915) de Pérez Lugín. Además, en alguna otra novela, como Pío Cid (1898) de Ganivet.

61 Este motivo va a repetirse de forma sistemática en casi todas las novelas de internados religiosos, que forman una red de «hermanas gemelas».

62 Ortega y Gasset recuerda en su conocida reseña de diciembre de 1910, «Al margen del libro A.M.D.G», que a él también, como a Bertuco, le colgaron la cruz de Emperador en el colegio malagueño donde estudió. La reseña aparece reproducida por Amorós íntegramente, juntamente con otras también significativas de otros polemistas (A. Amorós, op. cit., pp. 32-36).
} 
día vi a Marujina, su hermana, cómo me gusta», 328), o bien la recurrente notificación de la muerte de los familiares.

La crítica ha destacado ${ }^{63}$ cómo la pieza teatral inserta dentro de A.M.D.G. con el título «Consejo de Pastores», aparte de suponer una muestra de flexibilidad con mezcla de materiales narrativos heterogéneos propia de la novela lírica, es el pórtico que abre la serie de tres capítulos previos a la inserción del episodio de los ejercicios espirituales en los que se glosan los tres modelos pedagógicos que representan, respectivamente, el padre Sequeros, el Prefecto de disciplina, Conejo y el padre Mur, bajo los títulos inequívocos de «Pedagogía Laxa», «La pedagogía de Conejo»y «Mur, pedagogo». La descripción de los ejercicios espirituales cobra después, en efecto, una importancia capital dentro del anecdotario colegial, expresada gráficamente a través del diseño editorial, con un capítulo situado en la parte central de la novela bajo el título latino de «Vive memor Lethi», alusivo al tema de la muerte como centro de la edificación interior de la pedagogía jesuítica. El capítulo inserta los apuntes de que se auxilia el director de los ejercicios, el padre Olano. Proliferan los enunciados en mayúscula; las notas en caracteres más pequeños que los habituales; signos visuales de la iconografía cristiana; poemas intercalados, notas marginales o apostillas. ${ }^{64} \mathrm{Y}$ es tal vez en este capítulo donde el autor intensifica la utilización del léxico degradante ad hoc, casi siempre «esperpentizado» y con incidencia en el campo semántico de la descomposición orgánica, la mutilación y el apoyo de abundante sufijación despectiva. ${ }^{65}$

Acerca de la «pena del sentido»:

La pena de sentido es universal y atormenta todo el cuerpo y toda el alma. El condenado yace en el infierno siempre en aquel mismo sitio que le fue señalado por la Divina justicia, sin poderse mover, como en un cepo; el fuego de que está, como el pez en el agua, todo circuido, le quema alrededor, a diestra, a siniestra, por arriba y por abajo, la cabeza, el pecho, la espalda, los brazos, las manos y los pies, todo está penetrado de fuego, de manera que todo parece un hierro hecho ascuas, como si en este momento se sacase de la fragua (...) Mas este fuego no se queda sólo en el exterior, sino que pasa también al interior del condenado: penetra el cerebro, los dientes, lengua, garganta, hígado, pulmón, entrañas, vientre, corazón, venas, huesos, médula de éstos, sangre (in inferno erit...), y lo que es más terrible, este

63 «A.M.D.G. (...) ofrece cuadros variados cuyo denominador común es su sentido pedagógico, o aún mejor, su crítica de unos métodos pedagógicos». M. C. Bobes, «Renovación del relato en las primeras novelas de Ramón Pérez de Ayala», en AA. DD., Pérez de Ayala visto en su centenario, Oviedo, Instituto de Estudios Asturianos, 1981, p. 86. No obstante, todo ello va subordinado a la justificación de una psicología especial mostrada por el héroe en todo el conjunto novelesco de la tetralogía.

${ }^{64}$ La insistencia en la presentación de un diseño editorial expresivo para el motivo de los Ejercicios Espirituales se verifica de nuevo con más profusión aún en Mario en el foso de los leones de Federico Carlos Sainz de Robles.

${ }^{65}$ Modos expresivos que están siempre presentes en la novelística naturalista de internados, como Criadero de curas (1888) de Alejandro Sawa y Barrabás (1890) de José Zahonero. Estos novelistas presentan las historias escolares en espacio docente de seminario y colegio lazarista, respectivamente. 
fuego, elevado por divina virtud, llega también a obrar contra las potencias de la misma alma, inflamándolas y atormentándolas (243-244).

Bertuco padece, mientras duran los ejercicios, «dolorosos desfallecimientos y agonías interiores» (248); se oprime las sienes, se tritura los labios y desarrolla en definitiva, del mismo modo que en «El señor Cuenca...» y en Niño y grande, la consabida enfermedad incubada en tales momentos de aparato escénico jesuítico. Es empujado a la confesión general, pero lleva quince días de malestar, con pérdida de apetito, «insomne, laxo y con fuertes jaquecas». La enfermedad ya no abandona al muchacho, aunque se intercalen otras historias, hasta precipitar el desenlace. El escolar, brutalmente magullado por el padre Mur, es salvado en el último momento por un médico amigo de la familia que le restituye la salud y propicia la salida definitiva del recinto docente. Une su suerte con Bertuco el profesor «apestado» (Atienza) quien, tras emitir la conocida frase final de la necesidad de supresión de la Compañía (como Ortega en la reseña de esta novela), hace camino común hacia la rehabilitación personal conformando en realidad así la «pareja pedagógica», que tiene su correspondencia real con las biografías personales de Pérez de Ayala y de Julio Cejador.

La consideración positiva como educador total del alter ego de Julio Cejador (el padre Atienza) se ve corroborada otras veces en la voz de los alumnos, quienes lo califican de «gracioso» y «bueno» (157), capaz de mezclarse con los muchachos en medio de los juegos del recreo repartiendo «estampas», regalando «confites» o dando «cariñosos capones y azotainas paternales» (157). Su línea pedagógica es apoyada de algún modo por los otros profesores «positivos» como Sequeros, que comparte ex aequo el cariño de los escolares y es adorado por las «madreselvas». Adolece, sin embargo, de exceso de laxitud educativa. El propio Atienza estima que «su fuego apostólico excesivo» pone en ridículo a la Compañía. ${ }^{66}$ El padre Urgoiti, por otro lado, es «un santo varón para quien no existía la realidad externa» (156), dulce y manso, que sin embargo no tiene miedo al superior (156).

Entre los profesores clérigos que funcionan como oponentes al intento de encauzamiento pedagógico sobresalen Arostegui y Mur, cuyos comportamientos son subrayados por medio del recurso de la caricatura y de la animalización de filiación naturalista. La nariz del padre Mur es «un morro puntiagudo y vibrátil como el de las ratas de alcantarilla» (144). «La rubicunda nariz (del padre Mur) inquisitiva y husmeante, que, en lo más avanzado de su punta, se complicaba manifestando turgente y sanguinolenta verruga» (154) o, con metonimia quevedesca, «en su lugar, la temerosa e ingente nariz de Mur avanzaba por el claustro, de la salida del comedor,

66 J. G. Maestro, «Semiología del personaje literario en A.M.D.G, de Ramón Pérez de Ayala», Boletín del Instituto de Estudios Asturianos, XLIII, 131 (1989), p. 511. 
trayendo en pos, casi escondido al citado jesuita» (305). El personaje Mur funciona así como ariete en el trabajo opresivo que lleva a cabo el bando oponente para conjurar cualquier tipo de cambio pedagógico. La valoración moral del mismo viene expresada por procedimientos lingüísticos que intensifican los conceptos de acritud y de desdén, en consonancia con el tenor de su práctica educativa, la cual se basa en el postulado de que el hombre es malo por naturaleza. Asimismo, el padre Arostegui, con presencia más discontinua en la novela, es caracterizado sistemáticamente por los rasgos de la rigidez y del hermetismo y se configura como un personaje plano. ${ }^{67}$ En suma, los personajes profesores, que en su mayor parte encajan en el entramado de la novela como «tipos» descritos por adjetivos caracterizadores, apuntan en su conjunto al tema central de la educación ${ }^{68}$ en unos momentos en que la sociedad española está fuertemente pedagogizada. ${ }^{69}$

Dentro de la tonalidad anticlerical innegable que presenta A.M.D.G., subyace en el ánimo del artista un espíritu de estirpe erasmista, al que se ha referido siempre Amorós en sus conocidos estudios, y una preocupación por el hecho religioso que se mantiene y modula a lo largo de su trayectoria literaria (no participa, por ejemplo, del espíritu que anima al montaje teatral en tiempos de la República) llegando, como es bien sabido, a ponderar la importancia que tuvo la Compañía de Jesús en la conformación de un sistema educativo de España y de su propia educación personal. ${ }^{70}$ Toda una retractación que se produce también en algún otro autor (Azorín) cuando valora retrospectivamente sus primeras obras literarias. ${ }^{71}$

67 J. G. Maestro, op. cit., p. 519.

68 A. Amorós, op. cit, p. 87.

${ }^{69}$ M. D. Albiac recuerda que A.M.D.G. está fechada precisamente el año del fusilamiento de Ferrer Guardia en los fosos de Montjuic («Hidalgos y burgueses: la tetralogía generacional de Ramón Pérez de Ayala», en AA. DD., Ideología y sociedad en la España contemporánea, Madrid, Cuadernos para el Diálogo, 1977, p. 218. Ver de la misma autora, «Autobiografía personal y biografía generacional en la obra de Ramón Pérez de Ayala», en AA. DD, L'autobiographie en Espagne, Actes du II Colloque International de La Baume-Les-Aix, Université de Provence, 1982, pp. 181-201. Son momentos en los que Pérez de Ayala escribe una serie de artículos periodísticos sobre la cuestión educativa en El Imparcial, o en los que visita la Universidad de Madrid y la de Granada, con la consiguiente toma de contacto en esta última ciudad con las Escuelas del Ave María del Padre Manjón. Es época de plena sintonía con el partido republicano de Melquíades Álvarez. Se pone en marcha, además, el proyecto socialista de Núñez de Arenas de la «Escuela Nueva» (M. Tuñón de Lara, Medio siglo de cultura española (1885-1936), Madrid, Tecnos, 1984, pp. 164 y ss.). Ver además F. Friera, Ramón Pérez de Ayala testigo de su tiempo, Gijón, Fundación Alvargonzález, 1997, pp. 89-101; y A. Coletes, «Educación y pedagogía en Ramón Pérez de Ayala», Aula Abierta, Revista del ICE de Oviedo, 30 (1980), pp. 29-50.

70 M. G. O’Brian, El ideal clásico de Ramón Pérez de Ayala en sus ensayos en «La Prensa» de Buenos Aires, Oviedo, Instituto de Estudios Asturianos, 1981.

71 Ayala publica una serie de artículos en $1942(521,524)$ en los que defiende sin paliativos la labor educadora de la Compañía, y le atribuye el valor de preservación de la cultura. El artículo «Los jesuitas y las humanidades» (en R. Pérez de Ayala, Nuestro Séneca y otros ensayos, Barcelona, EDHASA, 1966), sostiene, por ejemplo, que la continuación del estudio de las Humanidades en la segunda enseñanza española se debe al sistema de la Ratio Studiorum. A diferencia de lo que sucede en Inglaterra, los institutos 
Cuando Gabriel Miró da a las prensas en 1909 la novela Amores de Antón Hernando con el número 48 de «Los Contemporáneos», con ilustraciones de Romero-Calvet, está cumplimentando su primer periodo literario de aprendizaje que comprende el primer decenio del siglo xx, rematado en 1910 con la publicación de Las cerezas del cementerio. ${ }^{72}$ Muestra en este periodo insistencia en la exploración de modelos novelescos autobiográficos con historias de autoformación, insertas dentro del subgénero de la novela lírica. Años más tarde da ampliación a este texto y aparece definitivamente en 1922 con el título Niño y grande.

Aunque no incluyó la primera versión en sus «Obras Completas», parece oportuna la consideración de la novela de 1909, dado que antecede a A.M.D.G. de Pérez de Ayala. Aparece vinculada estrechamente, también en cuanto a la cercanía temporal, al relato corto «El señor Cuenca y su sucesor (Enseñanza)», que tiene fecha inicial de 1908 y es publicado por primera vez en Los lunes de El Imparcial, el 25 de noviembre de 1911, para pasar como una parte de libro en $1917 .{ }^{73}$ Este último relato corto dibuja unos frailes coercitivos e inquisidores que tratan con saña a los escolares castigados (al alumno Señor Cuenca, por caérsele las medias), con el punto culminante de los ejercicios espirituales, momento en el que los educandos «se pierden» y gritan durante el momento de las plegarias, como desahogo vengativo, por el silencio que se les impone (sucede lo mismo en Mario en el foso de los leones, 1925, de Sainz de Robles y en El convidado de papel, 1928, de Jarnés). El señor Cuenca, como consecuencia, según el narrador, de la represión a la que se ve sometido, muere el último día de los ejercicios espirituales. Sigüenza adulto adopta una posición de niño que revive y traslada el documento vivido. El compañero de viaje, insensible, es incapaz de captar el mensaje y facilita que su hijo ocupe el lugar dejado por Cuenca, convirtiéndose así en su sucesor. Es verdad que no hay despliegue de procedimientos satíricos contra la Compañía de Jesús tal y como se ofrece en otras obras afines de otros escritores. ${ }^{74} \mathrm{El}$ autor prefiere el arma de la ironía sobre la sátira y, sin embargo, en esta temprana composición está cifrada la configuración de las novelas de internado mironianas, las cuales apuntan siempre al daño producido por el sistema pedagógico en los espíritus sensibles de los educandos.

oficiales españoles han adaptado básicamente el plan de estudios de los jesuitas, por lo que la expulsión de los Jesuitas en España es reputada como perjudicial para la instrucción.

72 C. Ruiz Silva, op. cit., pp. 11-15.

${ }_{73}$ R. Landeira, op. cit., pp. 66-68. Precisa bien la genealogía de este relato, con interpretación acertada del mismo.

74 Por ejemplo, en la novelita de Joaquín Belda, Los nietos de San Ignacio (1916), que recoge algunas de las marcas del género narrativo antijesuítico, y que focaliza sarcásticamente «la muerte de siete días» que suponen los ejercicios espirituales, con niños que lloran de terror al final de cada meditación y que sienten espanto ante la visión plástica del Infierno, para delectación de algunos padres jesuitas. 
En todo caso, cuando Miró inserta en sus obras completas la versión definitiva de la primitiva Amores de Antón Hernando con el título de Niño y grande, mantiene la fecha de octubre de 1909, dando a entender que en ese momento estaba ya concebida la obra definitiva. ${ }^{75}$ La novelita se acoge al esquema de narración autobiográfica con el propósito de trazar un trayecto de aprendizaje que arranca de la inmersión del infante en el internado. La versión primera de 1909 queda así como una novela breve de cuatro capítulos y un epílogo trasladados con diferencias poco importantes a la versión de 1922, en las dos primeras partes (cada una de ellas recoge dos capítulos de la primera versión), titulados ahora «La hermana de Bellver» $\mathrm{y}$ «Doña Francisca», respectivamente. El epílogo contiene el inicio de lo que en la segunda versión forma la tercera parte, de una extensión próxima a la suma de las dos primeras. El título, en sintonía con los anteriores, es «Elena».

El componente de desgarro entre el amor y el deseo tiene en Niño y grande más recorrido que en Amores, y ha podido suscitar algún estudio reciente en clave de psicoanálisis freudiano. ${ }^{76}$ Por ejemplo, en su primera etapa novelesca (1901-1910), Miró compone obras que tratan literariamente el tema de la culpa, ${ }^{77}$ tal La novela de mi amigo (1908), con recreación de la figura del artista neurótico que vive atenazado por la autoinculpación de las muertes de hermana e hija. Y es que el ingrediente sexual (lo señala Ontañón de Lope ${ }^{78}$ ) adopta en la obra de Miró un valor crucial y suele convertirse en raíz del tormento íntimo que impide la búsqueda neta de la felicidad.

En fin, toda la anécdota argumental remite a esos cuatro años de estancia en el colegio rememorados en la primera parte, y no parece aventurado señalar que Las confesiones de un pequeño filósofo (1904) de Azorín actúa como falsilla que permite al autor iniciar la composición de su texto con la reviviscencia de los tiempos escolares. Se evoca, de forma menos pormenorizada que en A.M.D.G., la frialdad de la escuela; otras dependencias, como el convictorio, o departamento donde viven los educandos; el ambiente de grosería y de falta de disciplina; las peleas, las clases de Gramática, los juegos infantiles, los paseos de los jueves siempre en ternas, los compañeros dispares, abocetados con rasgos extremados y contrapuestos; la semblanza de los profesores, de entre los cuales se señala uno menos nocivo que establece algún puente con el

\footnotetext{
75 Ver H. Carpintero, Gabriel Miró en el recuerdo (con un epistolario inédito de Miró), Alicante, Caja de Ahorros Provincial, 1983, p. 141; M. A. Lozano Marco, por su parte, analiza el tránsito de la primera versión a la segunda y califica la obra de «novela problemática»: «Una novela problemática (1908-1922)», en AA. DD., La novelística de Gabriel Miró: nuevas perspectivas, Alicante, Diputación, 1993, pp. 27-65.

${ }^{76}$ C. E. García Lara, Gabriel Miró y las figuras del deseo, Universidad de Alicante, 1999, pp. 118-129.

77 C. Ruiz Silva, op. cit., p. 13.

78 P. Ontañón de Lope, «El despertar erótico de Antón Hernando (en Niño y grande) de Gabriel Miró», en L. López-Baralt y F. Márquez Villanueva (eds.), Erotismo en las letras hispánicas, México, Colegio de México, 1995, pp. 407-415.
} 
escolar adolescente; las visitas trimestrales de los familiares y los ejercicios espirituales, siempre orientados hacia la reflexión sobre la muerte.

De semejante pintura se extrae, como en A.M.D.G., la reprobación evidente de los modos pedagógicos, aunque el autor siempre se cuide de no incurrir en el ajuste de cuentas panfletario. ${ }^{79}$ Los resultados se adelantan al comienzo del capítulo III de esta primera parte («En los estudios»), servidos en una construcción estilística que apunta una vez más al campo semántico de la enfermedad y la mutilación:

La frialdad y el silencio de los estudios, del refectorio y de los claustros; los hondos pasadizos cavados dentro de los muros; las siniestras hornacinas de los dormitorios, en cuyas paredes se sentía la sombra pavorosa de un santo obispo de talla descomunal; la foscura y pesadez de los tejados y torres, donde bajaban las nieblas y volaban los vencejos y gavilanes, que yo contemplaba desde mi pupitre; lamentos de campanas, clase de gramática, zumbas de los antiguos, y la emoción de la dulce libertad del cielo y de los campos; todas mis sensaciones, ayudadas de mi flaqueza, me mustiaron y entristecieron y acabé por enfermar (Niño, 80-81).

Se evocan de pasada los movimientos y actitudes de las autoridades académicas. El Padre Prefecto que «nos avizoraba por encima de su breviario y recatado en un viejo rosal que florecía en la desnudez del claustro» (86); el Padre Rector, que es enterado del episodio vergonzante que cuesta castigo y reclusión a Antón (96), o un «hermano inspector» que acecha en horario nocturno, entrevisto como un pobre diablo.

Pero el único profesor que toma verdadero cuerpo en el relato es el Padre Salguiz, presentado con los rasgos del religioso apestado caído en desgracia. Tal perfil es motivo temático recurrente en las novelas del género y tiende a convertirse en personaje coadyuvante que trata de amortiguar los efectos deletéreos que la educación religiosa produce en los escolares. Aislado del resto de los hermanos, recluido en su cubículo y dotado de preparación científica superior a los demás profesores, se dice de él:

El padre Salguiz, varón gordo, casi redondo, muy sabio en Física, y principalmente en Astronomía, y nada sosegado, contraviniendo lo que Cervantes dijo de la quietud de esta naturaleza lardosa.

Al padre Salguiz o padre astrónomo, según se le llamaba, apenas lográbamos verle. Sólo algunas veces distinguíamos, por la crujía de oratorio, un costal con bonete que se nos escapaba, como si rodase, por una puertecita ferrada, donde comenzaban las escaleras, que subían retorciéndose a la cumbre en la más alta torre del colegio. Allí tenía su observatorio, y su lecho y morada, como un mago.

No entendía de predicaciones ni de enseñanza. No asistía a recreos en comunidad, ni a fiestas académicas. Siempre aislado, distraído y hosco. Murmurábase de él; sonreíamos comedidamente con los inspectores cuando le nombrábamos, pero se le respetaba por su grande saber (100-101).

79 C. Ruiz Silva, op. cit., p. 36. 
Cuando se despide del internado, el muchacho descubre los ojos llorosos del profesor astrónomo, afectado por la marcha del escolar («Al apartarme del portal sentí sobre mi frente el vuelo callado de las aves negras y la mirada del padre Salguiz», 106), en estampa literaria que tiene un correlato claro con el final de A.M.D.G., donde, sin embargo, el profesor caído en desgracia (Atienza) hace camino común con el escolar protagonista.

El motivo de los ejercicios espirituales se inserta en la parte final de este capítulo de Niño y grande como símbolo más expresivo de la educación tenebrista que distingue a los colegios de jesuitas. Se deja testimonio de cómo acusa el alumno la huella de aquellos días, al modo del Retrato del artista adolescente (1914) de Joyce. Como en el relato de El libro de Sigüenza, «El señor Cuenca...», los ejercicios espirituales llevan en sus entrañas la enfermedad física: «Enfermé de descontento, y, de nuevo, quedé tullido de reuma; y por las noches me daba calentura y delirio» (103).

Este marco colegial levanta el señuelo del amor y del sexo que persigue al aprendiz durante sus años de juventud, por lo que las mujeres pasan a convertirse en «maestras» que ayudan al protagonista a sedimentar sentimientos. La trayectoria formativa ha configurado al personaje principal como un «joven artista adolescente», que sanciona precisamente esa condición en el momento de la construcción literaria de la novela. Como en Las confesiones de un pequeño filósofo de Azorín, el autor se sirve del breve capítulo descriptivo evocador de sensaciones minúsculas en una novela sujeta a la primera persona narrativa que hace continuados guiños también al género picaresco (particularmente al Lazarillo), con señalamiento de hitos en la formación del desengaño, en contraste con el sensualismo delicuescente que desarrolla la extraordinaria sensibilidad del artista adolescente.

Por lo que respecta a las novelas de Oleza, se desprende asimismo de ellas una crítica sociorreligiosa y una cierta ideología reformista al modo de A.M.D.G. ${ }^{80} \mathrm{Y}$ aunque El obispo leproso no sea en sentido estricto una novela de colegial, tampoco lo es Nuestro Padre San Daniel, complementa las costumbres escolares esbozadas en Niño y grande. El paso por el colegio «Jesús» no ocupa muchas páginas, pero el influjo de la orden se infiltra por toda la novela, de la que se extraen notas pedagógicas adicionales que redondean el anecdotario escolar realista. ${ }^{81} \mathrm{Y}$ así, se insiste en la férrea disciplina escolar con castigos severos, la separación en castas de los educandos, el aburrimiento y el sopor de los estudios o la excesiva pompa en los actos académicos públicos.

80 C. Longhurst, «Ideología reformista en Gabriel Miró. La crítica sociorreligiosa en las novelas de Oleza», en M. Samaniego y V. de Arco (eds.), Historia literaria y pensamiento. Estudios en Homenaje a María Dolores Gómez Molleda, vol. 2, Universidad de Salamanca, 1990, p. 59.

81 M. Ruiz Funes, op. cit., pp. 52-57. 
Las estampas de profesores, siempre irónicas, tienen a veces más enjundia aquí que en Niño y grande. Así, el señor Hugo, profesor de Gimnasia, rubio y sueco, es envidiado por su aspecto físico:

El señor Hugo, muy encendido, muy extranjero, de facciones largas, de una longura de adolescente que estuviera creciendo, y crecidas ellas más pronto semejaban esperar la varonía; también el cuerpo alto, de recién crecido, y el pecho de un herculismo profesional. Al destacarse, se le erizaba una cresta suntuaria de pelo verdoso. Erguido y engallado, como si vistiese de frac, su frac bermejo de artista de circo (146).

Don Roger, titular de Música («profesor de solfeo y bajo solista»):

Todo ancho, redondo, dulce. Cejas, nariz, bigote, boca, corbatín y anillo, manos y pies muy chiquitines. El vientre le afollaba todo el chaleco de felpa naranja con bastoncitos de cuentas de vidrio; los pantalones, muy grandes, le manaban ya torrencialmente desde la orla de su gabán color de topo, desbordándole por las botas de gafas y contera. Nueve años en la ciudad, y todos creían haberle visto desde que nacieron y con las mismas prendas, como si las trajese desde el principio y para siempre. Le temblaban los carrillos y la voz rolliza, como otro carrillo. Se ponía dos dedos, el índice y el cordal, de canto en medio de los dientes; los sacaba, y por esa hendidura le salía, de un solo aliento, un fa que le duraba dos minutos (147).

El Padre Martí, «profesor de matemáticas gordezuelo y pálido» (146); o las figuras equivalentes al padre Salguiz, el padre Fernando, a quien escoge el obispo como confesor por su humildad y caridad.

El narrador adopta una actitud burlona cuando da cuenta de la teatralidad de los movimientos de los religiosos profesores, el modo de pasear por parejas, el prurito de ocultar el nombre propio en beneficio del cargo eclesiástico, la focalización de la mirada torva o hiriente de alguno de ellos, o la insistencia, como hace Pérez de Ayala, en las insuficiencias formativas que tienen los padres en las materias académicas. Toda una requisitoria, en la que el autor evita el tono panfletario, en beneficio de la breve pincelada alusiva e irónica.

Como en Niño y grande, la estructura novelesca de El obispo leproso acoge un cierto recorrido educativo del protagonista, Pablo, en ambiente jesuítico. Este, mellado por la educación recibida en el internado, trata de conjurar la opresión por medio de actuaciones que intentan contrarrestar la carga autoritaria que le ha sido inoculada. Estas se manifiestan, como en la novela de internado inicial, en los ámbitos íntimos de la sexualidad (se ha recordado cómo Pablo recurre a grabados de monjas y torturas, incluso las abiertamente sexuales, en libros de edificación cristiana, utilizándolos a la manera de un Play-boy de la época). ${ }^{82}$ De igual modo, el paso del Pablo adolescente

82 I. Macdonald, «Introducción» a la edición de El obispo leproso de G. Miró, Fundación Cultural Caja de Ahorros del Mediterráneo, Instituto de Cultura Juan Gil-Albert, 1994, p. 57. Señala la capacidad de 
por un espacio cercenado por los valores antinaturales propicia el desarrollo de la sensibilidad de artista, con paladeo sensorial de su entorno y circunstancia. Como telón de fondo, el inevitable dibujo entre dos bloques de personajes a la manera de novelas como Doña Perfecta (1876) de Galdós, entre conservadores y liberales. ${ }^{83}$ Estos se identifican con los microcosmos espaciales, cerrados y abiertos respectivamente, con lo que la confrontación entre expansión y clausura remite simbólicamente a los dos sectores ideológicos de los personajes. ${ }^{84}$

\section{Conclusión}

La narrativa lírica española incorpora algunas notas propias del género novelístico Bildungsroman, tales como «intelectualización» o «memorialismo», para modelar una serie literaria que indaga en espacios colegiales opresivos. En los dos autores considerados, Pérez de Ayala y Miró, este subgénero novelístico de autobiografías de colegio posibilita aplicar la «crítica de la cultura», consustancial en la obra literaria de la generación literaria novecentista, ${ }^{85}$ al hilo en este caso de la reflexión sobre el sistema educativo de los Jesuitas. Aunque conecten con una tradición literaria antijesuítica anterior, A.M.D.G., Niño y grande, las novelas de Oleza y algún otro relato breve de Miró forman parte de una red de narraciones de internados religiosos escritas también por autores como Azorín, Julio Cejador, Joaquín Belda, Azaña, Federico Carlos Sainz de Robles o Benjamín Jarnés.

La base lírica de la que brotan las obras de Pérez de Ayala y Miró permite la composición de novelas de formación que derivan hacia estructuras de Künstlerroman o «de artista». En los dos casos sus autores conforman estructuras truncadas o antiformativas, siguiendo de cerca la estela de la novelística naturalista radical, aunque con atenuación del alegato anticlerical característico de la narrativa antijesuítica de época anterior. Importa en los dos casos, más en A.M.D.G. que en las obras de Miró, la consideración sistemática del cuerpo doctrinal transmitido a modo de tratado pedagógico, aunque sea mediante la puesta de relieve de tesis que han de interpretarse a contrario. Asimismo, el componente retórico de entretenimiento queda reforzado mediante la recreación de anécdotas escolares relacionadas con los distintos

Miró para convertirse en un adelantado de su tiempo al recrear literariamente las neurosis de represión sexual, como factor explicativo de los comportamientos retrógrados de las gentes de España.

83 R. Jonhson, El ser y la palabra en Gabriel Miró, Madrid, Fundamentos, 1985, p. 175, corrobora el parecido entre las novelas de Galdós y Miró.

84 R. Perelmuter Pérez, «Hermetismo y expansión en dos novelas de Gabriel Miró», Hispanófila, (1980, en.), pp. 47-57.

85 J. C. Mainer, «Manuel Azaña y la crítica de la cultura», en V. A. Serrano, y J. M. San Luciano (eds.), Azaña, Alcalá de Henares, Colegio del Rey, 2a ed. corregida y aumentada, 1991, p. 399. 
«tipos» profesorales y con las «costumbres» escolares cotidianas. Hay por aquí alguna conexión con la novela de costumbres universitarias, cuyo paradigma lo representa en esos momentos La casa de la Troya (1915) de Pérez Lugín.

La narrativa de colegios, y estos dos casos analizados lo acreditan, presenta como marca recurrente un conjunto de profesores que trabaja para la desintegración del discente dentro del espacio docente opresivo. Y por eso todas las instancias editoriales de las narraciones insisten en señalar los procedimientos antipedagógicos de los maestros, con recreación sistemática de un ambiente represivo en el que esos profesores aparecen dibujados con suficiencia expresiva por el camino del humor y la «esperpentización» galdosianos, con más nitidez en Pérez de Ayala, corroborando así la vinculación de este tipo de novelas con la tradición del Realismo y Naturalismo. 